\title{
Effects of a kindergarten intervention on vegetables served and staff's food-related practices: results of a cluster randomised controlled trial - the BRA study
}

\author{
Anne Himberg-Sundet* (1), Anne Lene Kristiansen, Lene Frost Andersen, Mona Bjelland \\ and Nanna Lien \\ Department of Nutrition, Institute of basic medical Sciences, Faculty of Medicine, University of Oslo, Norway
}

Submitted 31 January 2019: Final revision received 20 August 2019: Accepted 10 September 2019: First published online 20 February 2020

\begin{abstract}
Objective: The aim of the current study was to evaluate the effect on frequency, variety and amount of vegetables served and staff's food-related practices in the multicomponent BRA intervention.

Design: Cluster randomised controlled trial, conducted between Spring 2015 and Spring 2016. For allocation of the kindergartens, a stratified block randomisation was used. Data were collected in three ways: (i) a questionnaire for pedagogical leaders assessing the variety and frequency of vegetables served, including staff's food-related practices assumed to be related to vegetable intake; (ii) a questionnaire for kindergarten assistants assessing staff's food-related practices; (iii) a 5-d weighted vegetable diary assessing amount of vegetables served in a department.

Setting: The target group for this study was public and private kindergartens in the counties of Vestfold and Buskerud, Norway.

Participants: A total of seventy-three kindergartens participated.

Results: At follow-up I, the amount of vegetables served increased by approximately $20 \mathrm{~g}$ per person per day $(P=0.002)$, and the variety in served vegetables increased by one-and-a-half kind per month $(P=0.014)$ in the intervention group compared to the control group. No effects on the frequency of vegetables served or on staff's food-related practices were found.

Conclusions: The BRA intervention was successful in increasing the amount and variety of vegetables served within intervention kindergartens. Further research is needed to understand the mechanisms that can affect the staff's food-related practices.
\end{abstract}

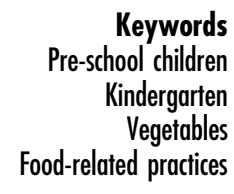

Vegetables are an important part of a balanced and healthy diet, and evidence supports a positive association between a higher intake of vegetables and health benefits ${ }^{(1)}$. Despite this evidence, the recommended vegetable intake is still not met in many countries ${ }^{(2)}$. Therefore, increasing daily vegetable intake in the population is of high public health importance and has been highlighted by health authorities at all levels ${ }^{(1,3,4)}$. Evidence suggests that dietary behaviours established early in life track into adulthood ${ }^{(5-8)}$, which makes childhood a critical period for establishing longlasting dietary habits ${ }^{(7)}$.

The food provided or made available for children is greatly influenced by adults, both at home and in various types of childcare. Vegetables available in the home/ childcare facility and the accessibility (vegetables in a ready-to-eat form) of vegetables seems to be important determinants for increasing vegetable intake in schoolaged children and youth ${ }^{(9-11)}$. In addition, evidence shows that parents play a crucial role in encouraging and supporting their children in eating healthy through modelling healthy habits ${ }^{(11)}$. For children too young to attend school (Norwegian children attend school in the autumn the year they turn 6), the use of out-of-home childcare has rapidly increased over the years, and parents are now sharing the responsibility for their children's diet with childcare providers. Limited research has examined the role of childcare staff's modelling behaviour; however, studies have shown positive associations between food-related practices in childcare and children's food ${ }^{(12)}$ and vegetable intake ${ }^{(13)}$. Childcare staff is, to a large extent, in control 
of the children's food environment during the day, and it seems important to ensure a supportive environment to increase children's vegetable intake.

Several interventions have been conducted to better understand what increases children's vegetable intake among children below 5 years ${ }^{(14,15)}$. However, interventions focusing on increasing vegetable intake among children in childcare settings are limited. The latest review of interventions for increasing fruit and vegetable consumption targeting children up to 5 years found little consistent evidence across studies ${ }^{(15)}$. In addition, multicomponent studies were more successful in increasing vegetable consumption than single-exposure strategies ${ }^{(14)}$. A severe amount of research has been conducted on the primary outcome - vegetable intake in/among children ${ }^{(14,15)}$, but very few studies report on the secondary outcome - vegetable/ dietary changes in the kindergarten environment.

The present study was conducted in Norway, where $91 \%$ of all children aged $1-5$ years are attending kindergarten, and the majority of these children spend $\geq 41 \mathrm{~h}$ per week in the kindergarten ${ }^{(16)}$. There are normative national guidelines for food and meals served in Norwegian kindergartens ${ }^{(17)}$. These guidelines specify that vegetables and fruit/berries should be included in each meal and that kindergartens should provide for at least two nutritional full meals a day ${ }^{(17)}$. In addition, kindergartens have a framework plan for their content and tasks, which underlines that the kindergarten has a responsibility to contribute to teaching children about healthy dietary habits ${ }^{(18)}$. Meals are either brought from home (lunch box) or provided by the kindergarten, or a combination of both. The kindergarten food procurement system differs between municipalities and ownership. Kindergartens in Norway are either public or private, where private kindergartens are run by companies and public kindergartens are run by municipalities. However, the kindergarten law and associated guidelines apply to all kindergartens despite ownership.

The aim of the current study was to evaluate the effect of an intervention study to increase frequency, variety and amount of vegetables served in the kindergarten setting, and to evaluate the effect of the intervention on changes in staff's food-related practices in the kindergarten from baseline to follow-up I.

\section{Methods}

\section{Study design}

The BRA study (an acronym for the Norwegian words Barnehage (kindergarten), gRønnsaker (vegetables) and fAmilie (family)) is a cluster randomised controlled trial with an overall aim to improve vegetable intake (primary outcome) among preschool children (3-5 years at baseline) through changing the food environment and foodrelated practices both in the kindergarten and at home (secondary outcomes), with immediate follow-up. More specifically, the secondary outcome in the kindergarten was to increase the weekly frequency and daily amount of vegetables served in this setting and to increase the variety of vegetables served over a month. In addition, to change the staff's food-related practices towards being more supportive of children tasting and eating vegetables. Baseline and follow-up I data from the kindergartens were used in the present study.

\section{Subjects}

The primary target group for the BRA study was preschool children born in 2010 and 2011, attending public or private kindergartens in the counties of Vestfold and Buskerud, Norway. All 479 public and private kindergartens were firstly invited by letter to participate in the BRA study. Then, all kindergartens were called to inform about the study and to motivate for participation. Seventy-three kindergartens chose to participate (response rate $15.2 \%$ ) (Fig. 1). These were randomised into intervention ( $n$ 37) and control ( $n$ 36) groups (Fig. 1). The kindergarten employees were the secondary target group for the intervention. Norwegian kindergartens often include multiple departments. These departments consist of approximately eighteen children, either children of the same age or children of mixed age. Each department is usually staffed with one pedagogical leader with the formal responsibility for the department, in addition to two or more assistants. The following study presents data collected from pedagogical leaders and assistants in departments where children born between 2010 and 2011 attended. Originally there were 135 departments participating in the BRA study; however, a total of seventeen departments were lost to follow-up I. Ten were lost due to incomplete data at baseline, and seven were lost due to reorganisation in the kindergarten (Fig. 1). In addition, some departments were excluded from analyses due to missing data on outcome measures (Fig. 1). This resulted in 96 (variety and frequency of vegetables), 86 (amount of vegetables) and 102 (staff's food-related practices) departments having complete data at baseline and follow-up I. This study was conducted according to the guidelines laid down in the Declaration of Helsinki, and all procedures involving human subjects were approved by the Norwegian Center for Research Data. All kindergartens agreed to participate in the BRA study by the kindergarten leader signing a written informed consent ( $n$ 73).

\section{Randomisation}

For allocation of the enrolled kindergartens, stratified block randomisation was used based on ownership and number of participating children. Stratum one and two were public and private kindergarten, respectively. Stratum three and four was $\leq 10$ children and $>10$ children, respectively. Randomisation was conducted by a statistician not involved in the project, using the statistical software program $\mathrm{R}$. 


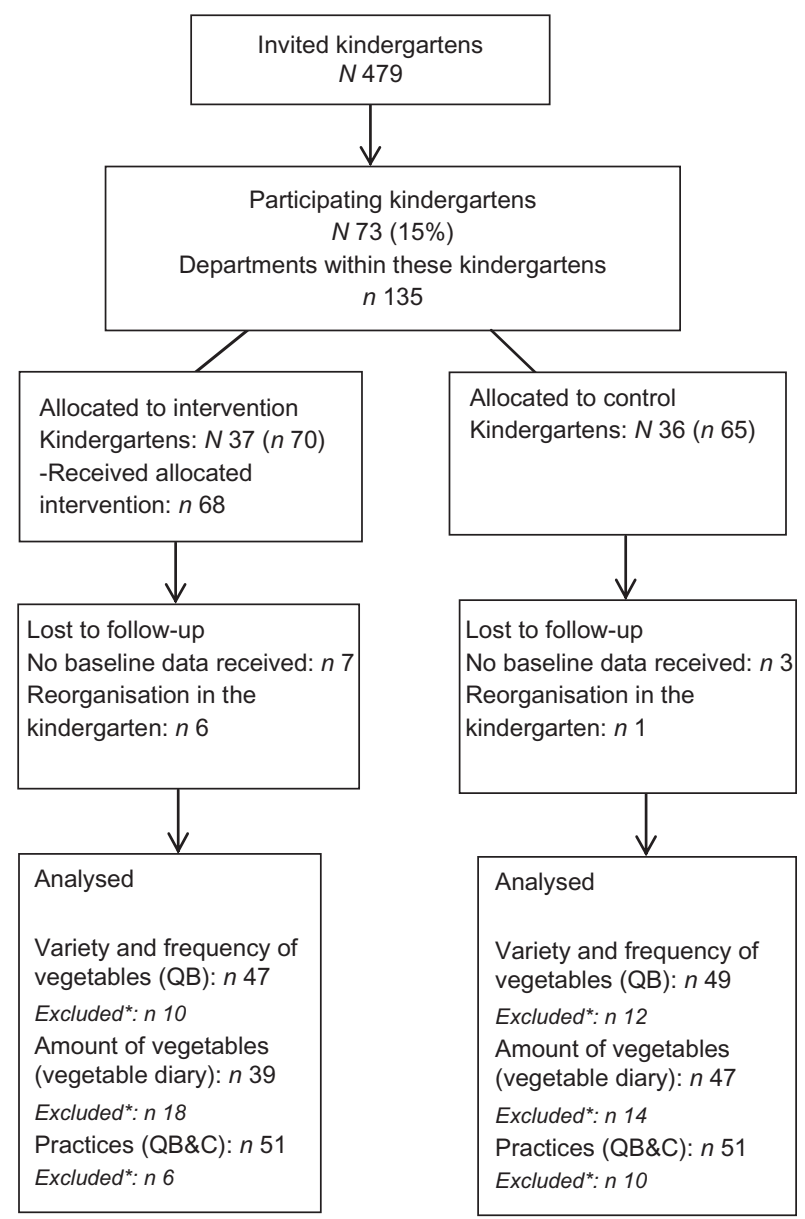

Fig. 1 CONSORT flowchart of recruitment, randomisation and participation of kindergarten and number of departments. $N=$ kindergartens; $n=$ departments

*Missing outcome measures

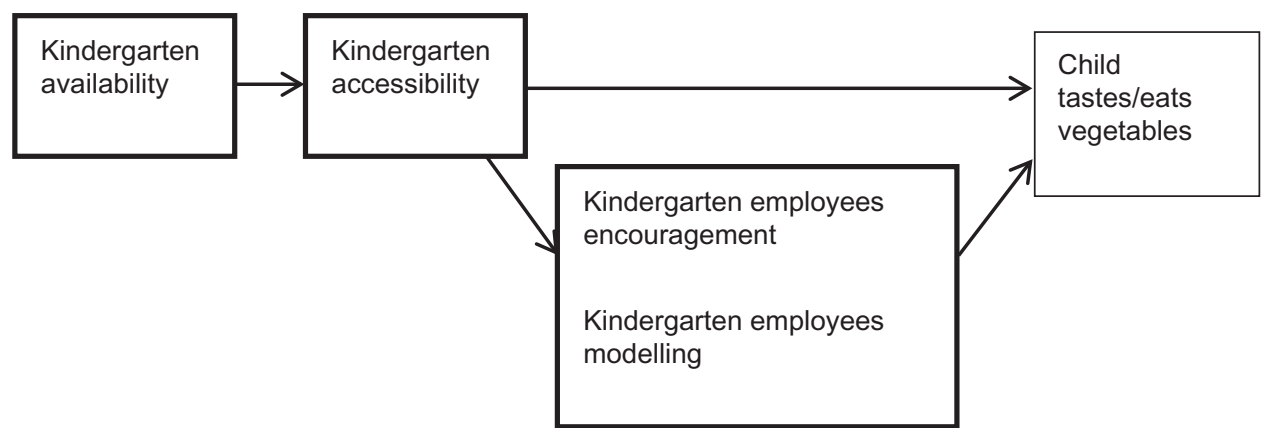

Fig. 2 The logic model of intervention in the kindergartens, the BRA study

\section{Intervention/control}

We hypothesised that the multicomponent intervention would make (i) staff change the availability and accessibility of vegetables in the departments, as well as their foodrelated practices (role modelling and encouragement) and through this (ii) vegetable intake among the 3-5-year-olds would increase (Fig. 2).
The intervention is described in accordance with the TIDieR guidelines ${ }^{(19)}$. Additionally, the TIDieR checklist (online supplementary material, Supplemental file 1) and the CONSORT checklist for cluster randomised controlled trials have been completed (online supplementary material, Supplemental file 2). Briefly, the intervention consisted of a $1-d$ inspirational course (kitchen practice and theory) for 
kindergarten staff and material for the kindergartens. The cook responsible for the kitchen practice observed and rehearsed the practical session developed by the Geitmyra culinary centre for children. The theoretical part was conducted by one principal investigator (NL) accompanied by either the post-doc (ALK) or the PhD student (AHS). The staff attending the course was responsible for informing and training the relevant personnel in their kindergarten. The kindergarten staff received a welcome package at the inspirational day, which included one large poster with photos of vegetables, six small posters made for the project with ideas of 'what to do' for each of the four determinants (availability, accessibility, encouragement and role modelling), aprons, brochures about the project, the Norwegian national guidelines for food and meals in the kindergartens ${ }^{(17)}$, the Norwegian dietary guidelines ${ }^{(31)}$ and one hand-blender per kindergarten. The implementation of the intervention by kindergarten staff was supported by developing their own action plans within 4 weeks after the inspirational day. Moreover, a login-protected website containing all materials, as well as additional information about forty-five vegetables and small articles about the four determinants, had been developed and was available for intervention kindergartens. The kindergarten staff was also invited to attend a closed Facebook group set up for the study. Booster activities were sent to the kindergartens, 2 and 5 months after the inspirational course. Booster activity 1 included a booklet with recipes on cabbage, a vegetable card/poster to register when and which vegetables were served for $3 \mathrm{~d}$ with potential for winning a gift card by sending it to the project group, a sheet with suggestions on how to play tasting games with the children. Booster activity 2 included a booklet with spring recipes like different vegetables to be included in salads and suggestions of activities to grow vegetables at three levels of difficulty.

The intervention components were delivered between September 2015 and February 2016, but the kindergartens were encouraged to implement and change their practices in accordance with their own plans. In August 2016 the kindergartens were e-mailed to encourage them to maintain any changes achieved and to continue to work on improving their practices around serving vegetables. Control kindergartens participated only by providing data and were offered access to the website in September 2017.

Both intervention and control kindergartens completing all questionnaires both in 2015 and in 2016 received a gift card with a value of 2000 NOK (approx. 223 EUR).

\section{Data collection}

Baseline data were collected during Spring 2015, and follow-up I data were collected during Spring 2016. A detailed description of data collection has been published previously ${ }^{(20)}$. In brief, data were collected by paper-based questionnaires (one for kindergarten leaders, one for pedagogical leaders and one for assistants), and a 5-d weighted vegetable diary (filled in by anyone working at the department). Modified items from statements and questions used in the last national dietary survey in kindergartens $^{(21)}$ and the last dietary survey among Norwegian 2-year-olds ${ }^{(22)}$ were used in questionnaires A, $\mathrm{B}$ and $\mathrm{C}$. These modified questions have not been tested for reliability or validity. Questions assessing kindergarten staff's food related-practices were measured by item pools composed of modified versions of statements used in previous international studies among parents ${ }^{(23-26)}$, and used in questionnaires B and C. Translation and back-translation of statements and questions available in English were conducted by fluent speakers of English and Norwegian languages. As descriptive data were collected at the kindergarten level through kindergarten leaders, and the outcome measures were collected at the department level through pedagogical leaders and assistants, these results are presented at two different levels.

\section{Measures}

Questionnaire A: characteristics of kindergartens Questions used from Questionnaire A were: 'Is the kindergarten public or private?', with two response alternatives: 'public' and 'private'. Four open-ended questions were included as well: "What is the total number of children in the kindergarten?', 'How many full-time equivalents do the kindergarten have?', 'How many full-time equivalents educated as kindergarten teacher do the kindergarten have?' and 'How much do the parents pay each month for food and beverages per child?' Kindergartens having 'written guidelines for food provided by the kindergarten' (Table 1) were those who reported having included this in 'the annual plan', 'in written guidelines' or 'in both the annual plan and written guidelines'.

\section{Questionnaire B: frequency and variety of vegetables} served

The weekly frequency of served vegetables for breakfast, lunch and afternoon meal was assessed through three separate questions: 'How often does your department offer vegetables for breakfast/lunch/the afternoon meal?' The response alternatives were on a seven-point scale ranging from ' $5 \mathrm{~d}$ a week' to 'never'. The monthly variety of vegetables served for lunch and for afternoon meal was assessed through two separate questions: 'How often does your department offer these vegetables for breakfast/lunch/the afternoon meal?' Twelve vegetable alternatives (cucumber, tomato, bell pepper, sugar snap peas, salad, carrot, corn, broccoli, cauliflower, rutabaga, cabbage, peas) were given with the same response alternatives as mentioned above.

\section{5-d weighted vegetable diary: amount of vegetables served}

A detailed description of the 5-d weighted vegetable diary has been published previously ${ }^{(20)}$. Briefly, the kindergarten 
Table 1 Baseline characteristics of kindergartens who participated in the BRA study by condition

\begin{tabular}{|c|c|c|c|c|c|c|c|}
\hline & \multicolumn{3}{|c|}{ Control (n 35) } & \multicolumn{3}{|c|}{ Intervention (n 34) } & \multirow[b]{2}{*}{$P$} \\
\hline & Mean & $\%$ & SD & Mean & $\%$ & SD & \\
\hline Private kindergartens & 14 & 40 & & 17 & 50 & & $0.404^{*}$ \\
\hline Public kindergartens & 21 & 60 & & 17 & 50 & & \\
\hline Number of children & 54 & & $22 \cdot 5$ & 57 & & $30 \cdot 1$ & $0.586+$ \\
\hline Full-time equivalent & 13 & & $6 \cdot 1$ & 14 & & $6 \cdot 8$ & $0.508 \dagger$ \\
\hline $\begin{array}{l}\text { Full-time equivalent educated } \\
\text { as kindergarten teacher }\end{array}$ & 6 & & $3 \cdot 0$ & 6 & & $3 \cdot 4$ & $0.419 \dagger$ \\
\hline $\begin{array}{l}\text { Additional payment for food } \\
\text { and beverages }\end{array}$ & $266 \ddagger$ & & $92 \cdot 2$ & $290 \ddagger$ & & $61 \cdot 0$ & $0.216 \dagger$ \\
\hline $\begin{array}{l}\text { Employees pay a monthly fee for } \\
\text { food and beverages: 'Yes' }\end{array}$ & 29 & $82 \cdot 9$ & & 26 & $76 \cdot 5$ & & $0.467 \dagger$ \\
\hline $\begin{array}{l}\text { Written guidelines for food } \\
\text { provided by the kindergarten: 'Yes' }\end{array}$ & 28 & 80 & & 29 & $85 \cdot 3$ & & $0.526^{*}$ \\
\hline
\end{tabular}

*Person's Chi-square test.

tIndependent sample $t$-test.

¥Norwegian kroner, 266 NOK $=29.03$ EUR and 290 NOK $=31.65$ EUR.

staff was instructed to weigh vegetables served for five consecutive days, both before and after each meal, and to report the number of children and adults present during the meal. This provided a measure of the amount of vegetables in grams served per person per day, through a typical week for breakfast, lunch and afternoon meal in the kindergarten.

\section{Questionnaires B and C: kindergarten staff's food-related practices}

The score labelled 'staff's food related practices' consisted of eight different factors, and items included in each factor are presented in Table 2. A detailed description on how the factors were extracted is published elsewhere ${ }^{(27)}$. The eight factors were: modelling (five items), initial encouragement (five items), child involvement (four items), reactive encouragement (three items), strictness (three items), rewarding (three items), accessibility (four items) and availability (three items) ${ }^{(27)}$. Response to each item were given on a five-point scale ranging from 'totally disagree' $(=1)$ to 'totally agree' $(=5)$, with a neutral midpoint. Reversed score was used for the items included in the factors labelled strictness and rewarding. Change in each factor from baseline to follow-up I was explored, but since no change was detected, they are presented as one overall score labelled 'staff's food-related practices'. Mean scores of each of the eight factors were added and then divided by eight to give the mean score for 'staff's food-related practice', and the overall score is presented in Table 2. Finally, this score was aggregated to the department level.

\section{Detectable effect sizes}

For the secondary outcome of detecting changes in kindergarten practices, SD's from the most relevant survey tools were used for the frequency of serving vegetables (days per week) $)^{(21)}$ and food-related practices ${ }^{(28)}$, respectively. With thirty kindergartens in each group, type 1 cut-point was $z_{\text {alpha }}=1.96$ for $P=0.05$ and type 2 cut-point was $z_{\text {beta }}=0.84$ for $P=0.2$, so the detectable effect size for $80 \%$ power was $1.96+0.84=2.8$ times the SE of the mean difference in outcome measure between groups ( $\mathrm{SE}_{\mathrm{trt}}$ diff). The SD for serving vegetables was 1.9 , and thus with $80 \%$ power, it would be possible to detect a difference in serving vegetables of $2 \cdot 8 * \mathrm{SE}_{\text {trt diff }}=2 \cdot 8 * \sqrt{ } 2 *\left(\mathrm{SD}^{2} / \mathrm{m}\right)=2 \cdot 8 \sqrt{ } 2 *$ $\left(1.9^{2} / 30\right)=1.4$ days per week. With an SD of 1.7 from the nutrition score in the NAP SACC study ${ }^{(28)}$, and with $80 \%$ power, it would be possible to detect a difference in nutrition score of $1 \cdot 23$. This is right on the border of the effect that was detected in the per-protocol analysis from NAP SACC ${ }^{(28)}$.

\section{Data analysis}

Statistical analyses were performed using the statistical software package $\mathrm{IBM}^{\circledR}{ }^{\circledR}$ SPSS ${ }^{\circledR}$ Statistics, version 24.0. Descriptive statistics were used to describe the study sample at baseline, and independent sample $t$-test and Person's Chi-square test was used to test for differences between the control and intervention groups at baseline. Since the intraclass correlation was $>5 \%$ when quantifying the degree of clustering, there was a meaningful difference among the groups ${ }^{(29)}$. The effect of intervention from baseline to follow-up I was explored by mixed-model analysis on differences between amount, frequency and variety of vegetables served and staff's food-related practices in the intervention and control groups on follow-up I values, adjusted for baseline measures and using intervention/control as the primary covariate of interest. Kindergarten was used as a random effect to account for random inhomogeneity between kindergartens. The models were inspected by looking at the residuals and Q-Q plots, which indicated a roughly normal distribution of data. Random intercept models were fitted, with group allocation and baseline measures as fixed effects. Only complete data, with measures from both baseline and follow-up I, were included in the analyses. The significance level for the analysis was set to $P<0.05$. 
Table 2 Items and factors that were added to the total score for 'staff's food-related practices'

\begin{tabular}{|c|c|c|}
\hline & \multicolumn{2}{|c|}{ Baseline } \\
\hline & Mean* & SD \\
\hline Modelling & $4 \cdot 21$ & 0.50 \\
\hline I show the children how much I enjoy eating vegetables & $4 \cdot 37$ & 0.67 \\
\hline I try to show enthusiasm about eating vegetables & $4 \cdot 22$ & 0.67 \\
\hline I model vegetable eating for the children by eating vegetables myself & $4 \cdot 72$ & 0.40 \\
\hline I try to eat vegetables in front of the children, even if they are not my favourite & 3.52 & 0.96 \\
\hline I show the children how to eat vegetables (mix with other foods, use as garnish, etc.) & $4 \cdot 20$ & 0.67 \\
\hline Initial encouragement & 3.38 & 0.59 \\
\hline I describe the consistency and/or taste of new vegetables for the children & $3 \cdot 32$ & 0.85 \\
\hline I show the children how they can explore vegetables with their senses & 3.41 & 0.79 \\
\hline I tell the children what kind of vegetables we are to eat & 4.00 & 0.72 \\
\hline I allow the children to play with vegetables (make figures, use as tusk, etc.) & $3 \cdot 17$ & 0.84 \\
\hline I refer to characters the children are familiar with from TV/books/plays that eat vegetables & 3.00 & 0.83 \\
\hline Child involvement & $3 \cdot 17$ & 0.59 \\
\hline I ask the children to choose vegetables for meals & $3 \cdot 15$ & 0.85 \\
\hline I ask the children to help select vegetables at the grocery store & $2 \cdot 87$ & 0.84 \\
\hline I let the children assist in preparing vegetables (peeling, cutting, put on plates, etc.) & $4 \cdot 27$ & 0.66 \\
\hline I add something to make vegetables taste better & $2 \cdot 41$ & 0.86 \\
\hline Reactive encouragement & 4.37 & 0.69 \\
\hline I tell the children that vegetables taste good & $4 \cdot 49$ & 0.58 \\
\hline I encourage the children to eat vegetables to become strong and healthy & 4.47 & 0.50 \\
\hline I encourage the children to try a few bites of vegetables & $4 \cdot 72$ & 0.48 \\
\hline I praise the children when I see them eating vegetables & 4.08 & 0.76 \\
\hline I offer the children vegetables they like & 4.09 & 0.57 \\
\hline Strictness $†$ & $4 \cdot 12$ & 0.62 \\
\hline The children should always eat all the vegetables on their plates & 4.36 & 0.67 \\
\hline I insist that the children should sit at the table until all vegetables on their plate are eaten & 4.33 & 0.76 \\
\hline I am strict with the children concerning eating of vegetables & 3.60 & 0.79 \\
\hline Rewardingt & $4 \cdot 13$ & 0.53 \\
\hline I offer the children their favourite foods in exchange for vegetable consumption & $4 \cdot 32$ & 0.61 \\
\hline I reward the children with something they like (not food) if they finish their plate with vegetables & 4.54 & 0.50 \\
\hline I tell the children to be just as good as other children when it comes to eating vegetables & 3.53 & 0.88 \\
\hline Accessibility at kindergarten & $4 \cdot 16$ & 0.65 \\
\hline I send the plate/bowl of vegetables around the table & 4.38 & 0.74 \\
\hline I place the plate/bowl of vegetables within the reach of children & $4 \cdot 17$ & 0.82 \\
\hline We usually have more than one kind of vegetables at the table so the children can choose & 4.32 & 0.82 \\
\hline We usually serve vegetables separately so the children can choose which one they want & 3.77 & 0.86 \\
\hline Availability at kindergarten & $4 \cdot 15$ & 0.92 \\
\hline In our unit we usually vary the kinds of vegetables served for hot lunch & 4.03 & 0.76 \\
\hline $\begin{array}{l}\text { In our unit we usually vary the preparation method (raw, boiled, etc.) according to the types of } \\
\text { vegetables served for hot lunch }\end{array}$ & 4.09 & 0.78 \\
\hline In our unit we usually have vegetables at hot lunch every day & $4 \cdot 32$ & 0.71 \\
\hline Staff's food-related practices & 3.90 & 0.29 \\
\hline
\end{tabular}

*Responses were given on five-point scales, ranging from 'totally disagree' $(=1)$ to 'totally agree' $(=5)$, with a neutral midpoint. †Reversed score.

\section{Results}

From an eligible pool of 479 kindergartens, seventy-three kindergartens and 135 of their departments participated in the study. The BRA study had almost the same share of public and private kindergartens, compared to kindergartens in Vestfold and Buskerud counties. Furthermore, kindergartens in these counties had a mean of 12.5 full-time equivalents, and a mean of $4 \cdot 1$ employees with formal education, compared to the kindergartens in the BRA study, which had a mean of 13.9 full-time equivalents and 5.9 with formal education ${ }^{(20)}$. No significant differences in baseline characteristics were detected between control and intervention groups at the kindergarten level (Table 1). As previously mentioned, some departments were lost to follow-up I, leaving 118 departments to be analysed (fifty-seven departments in the intervention group and sixty-one departments in the control group) (Fig. 1).

At the department level, the mean score for each of the eight different factors included in 'staff's food-related practices' and the score for 'staff's food-related practices' are presented in Table 2.

Scores for intervention and control groups at the department level for frequency, variety and amount of vegetables served, and staff's food-related practices are presented in Table 3. Results from the mixed-model analyses showed an increased variety of one-and-a-half type of vegetables used per month in favour of the intervention group. An estimated increase in the amount of vegetables served, by serving approximately $20 \mathrm{~g}$ more vegetables per person per day, was observed in the intervention group compared 
Table 3 Intervention and control kindergartens at department level at baseline and follow-up I, including the estimated effect of the intervention in the BRA study*

\begin{tabular}{|c|c|c|c|c|c|c|c|c|c|c|c|}
\hline & \multicolumn{4}{|c|}{ Intervention } & \multicolumn{4}{|c|}{ Control } & \multicolumn{3}{|c|}{ Intervention effect† } \\
\hline & Baseline & SD & Follow-up I & SD & Baseline & SD & Follow-up I & $\mathrm{SD}$ & Estimate & $\mathrm{Cl}$ & $P$ \\
\hline Frequencył & 7.5 & $3 \cdot 1$ & $10 \cdot 4$ & $2 \cdot 3$ & $6 \cdot 8$ & $4 \cdot 2$ & $9 \cdot 2$ & 3.0 & 0.9 & $-2 \cdot 0,0 \cdot 1$ & 0.101 \\
\hline Variety & $8 \cdot 3$ & $2 \cdot 6$ & $9 \cdot 3$ & $2 \cdot 3$ & $7 \cdot 1$ & $3 \cdot 3$ & $7 \cdot 3$ & 3.5 & 1.5 & $0.3,2.6$ & 0.014 \\
\hline Amount§ & $47 \cdot 3$ & $18 \cdot 8$ & $64 \cdot 2$ & $27 \cdot 4$ & 41.2 & 28.2 & 40.9 & $27 \cdot 0$ & 20.5 & $8 \cdot 1,33.0$ & 0.002 \\
\hline Practices\| & 4.0 & 0.2 & $4 \cdot 1$ & 0.2 & 3.9 & 0.3 & 3.9 & 0.2 & 0.05 & $-0.1,0.0$ & 0.235 \\
\hline
\end{tabular}

The significant $P$ values are in bold.

*Weekly frequency, monthly variety and daily amount of served vegetables and staff's food-related practices scores.

tEffect analyses were adjusted for kindergarten clustering and baseline measures.

fIntervention ( $n$ 47), control ( $n$ 49).

§Intervention ( $n$ 39), control ( $n$ 47).

||Intervention ( $n 51)$, control ( $n 51)$.

to the control group (Table 3). No significant associations were found for the frequency of vegetables served during a week or for change in staff's food-related practices.

\section{Discussion}

This study showed a significant positive effect of the intervention on the variety and amount of vegetables served in the kindergarten. No significant effects were observed for the frequency of vegetables served during a week or for changes in staff's food-related practices.

\section{Effect of the intervention on amount, variety and frequency of vegetables served}

The availability of vegetables is one of the most important factors associated with increasing vegetable intake ${ }^{(9-11,30)}$. The positive effect of the intervention according to the variety and amount of vegetables served in the kindergarten might be a result of increased availability of vegetables in the kindergarten setting. The intervention components suggested how the kindergarten could increase the availability and accessibility of vegetables in the kindergarten setting. One example was how vegetables could be bought within the kindergartens' food budget, since the economy was a known barrier for providing healthy food in the kindergarten setting ${ }^{(21)}$, and this barrier was often supported by examples from some of the kindergartens present at the inspiration days. Further, as there are no specific recommendations for daily amount of vegetables for children in Norway, we chose to use a total daily intake of $180 \mathrm{~g}$ vegetables as the goal for children's vegetable intake. This is about $70 \%$ of the recommended intake for Norwegian adults $^{(31)}$. To reach this goal, the intervention components provided visual examples of what a portion size of $45 \mathrm{~g}$ vegetables per meal per child could look like. Furthermore, it was stressed that vegetables should be served at each meal. Together, these intervention components seem to have enabled the kindergartens to increase the availability and accessibility of vegetables. However, the intervention group increased the amount of vegetables served with only approximately $20 \mathrm{~g}$ per child per day. With a baseline average of approximately $40 \mathrm{~g}$ per child per day, there is still a potential to increase this amount further. The kindergarten should, at least, serve a portion size of $45 \mathrm{~g}$ two times per day to each child ( $90 \mathrm{~g}$ of vegetables a day per child) in terms of trying to reach the recommended intake of vegetables. We have not found comparable interventions with the aim to increase the amount of vegetables served in the kindergarten setting to discuss this result against.

According to the Norwegian information bureau for fruit and vegetables ${ }^{(32)}$, in addition to our own data (not shown), there are four commonly used vegetables in Norwegian kindergartens - cucumber, tomato, bell pepper and carrots. Both intervention and control groups had a high mean score at baseline for the variety of vegetables served. Still, a positive effect on increased variety of vegetables was seen in favour of the intervention group. This might be explained by the intervention components focusing on the importance of variation at the inspiration day and in booster activities 1 and 2 as well. Further, the majority of kindergarten leaders in the present study had knowledge of the national guidelines for food and meals in the kindergartens ${ }^{(20)}$, which promotes serving and eating a variety of foods ${ }^{(17)}$. Finally, a Belgium process evaluation study found that childcare staff thought it was very important to serve a variety of foods to promote children's taste development ${ }^{(33)}$. Thus, the message of variety along with the core message of the importance of encouraging the children to taste different/new vegetables might have resonated well with the staff in our study.

The frequency of serving vegetables did not increase significantly in intervention kindergartens compared to control kindergartens. The control group was encouraged to follow their usual routines; however, a significant increase in the frequency of served vegetables for both groups was confirmed by a paired samples $t$-test (data not shown). Such an increase in the control group might be explained by increased awareness in the control group through data collection in the BRA study. In particular, the weighing of vegetables could have contributed to this; moreover, control kindergartens could also have 
participated in other studies/projects focusing on vegetables or healthy eating. For the present study, the intervention components recommended the kindergartens to increase the frequency of served vegetables to three meals per day (breakfast, lunch and afternoon meal), which gives a possibility of fifteen vegetable servings per week. However, in the Norwegian guidelines for food and meals in the kindergartens ${ }^{(17)}$, it is stated that the kindergarten should provide for at least two nutritional full meals per day, which adds up to ten meals per week. Given that the baseline frequency was approximately seven servings per week, which is relatively high, this could have limited intervention kindergartens in increasing the frequency of served vegetables significantly.

\section{Effect of the intervention on staff's food-related practices}

Staff's food-related practices related to vegetable intake were not significantly different between the intervention and control groups at follow-up I. This is in accordance with the American NAP SACC intervention ${ }^{(28)}$ and an Australian intervention(34), targeting environmental changes of childcare centres, which did not find any effects for the nutrition part of their interventions ${ }^{(28,34)}$. However, the overall score on staff's food-related practices reported at baseline were relatively high, with a baseline score at approximately 4 . The range for this score was $1-5$, where a high score was assumed to be related with increased vegetable offer. An explanation for the lack of change might be that the employees felt that they were already conducting these practices, and since the baseline score was relatively high, this could have limited the possibility to increase this score further. However, two previously published cross-sectional studies ${ }^{(13,35)}$ found an association between childcare staff's modelling and children's vegetable intake. This emphasises the importance of continuing to study the role of staff's food-related practices and to understand the mechanisms that can affect the staff's food-related practices in childcare settings.

\section{Strengths and weaknesses of the study}

This study has several strengths. First of all, it was conducted in an understudied context, as few previous studies have investigated changes in the kindergarten food environment. Furthermore, there were no differences between the intervention and control groups for the baseline characteristics of the kindergartens, indicating that the randomisation was successful. We included three different outcomes of vegetables served (amount, frequency and variety), giving a broader picture of kindergarten vegetable practices compared to what has previously been reported. In addition, we used two different methods (questionnaires and the 5-d weighted vegetable diary), which were conducted by kindergarten staff working at all levels, giving a more complete picture of the practices. The multiple component intervention was developed based on 1.5 years of formative evaluation work and the logic model (Fig. 2). By using a multiple-component intervention, the kindergartens were given the opportunity to choose which adjustments they needed by developing their own action plans to change existing practices. A wide range of different kindergartens (in terms of size and how they were organised) participated, which may indicate that the intervention has a scalability potential for Norwegian kindergartens. How these might fit in the kindergartens in other countries will have to be assessed based on local knowledge.

However, the study also has some weaknesses. Even though the questionnaires were developed based on statements and questions used in previous studies and pilot-tested with small groups of staff from different kindergartens, they were not tested for reliability or validity due to a lack of time and resources. In addition, the questionnaires may not have been responsive enough to detect changes in staff's food-related practices despite tapping into many different practices. The 5 -d weighted vegetable diary could be filled in by anyone working in the department, and this could have caused a lack of consistency in how these data were reported both at baseline and follow-up I. However, it was important to make data collection easy for the staff to complete, and because the staff worked different shifts and were associated with different tasks, we decided that it would be more feasible for anyone working at the department to fill in the 5-d vegetable diary. In addition, the employees knew the purpose of the intervention, which may have affected the reporting of vegetables. Finally, missing data at baseline, reorganisation in kindergartens and missing outcome data reduced the number of kindergartens available for the analyses.

\section{Conclusion}

The multicomponent intervention was successful in increasing the variety and amount of vegetables served within intervention kindergartens. This study is one of few randomised controlled trials that have targeted the kindergarten environment to increase vegetables served to children. The results from the BRA study indicate that it is possible to increase the amount and variety of vegetables served without providing additional economic or staffing resources. An implementation of the intervention components in the kindergarten system may have a beneficial effect on public health. Such an intervention might also contribute to reduce social inequalities in health as children from all social classes attend kindergarten. Future research should seek to understand the mechanisms that can generate change in staff's food-related practices in the kindergarten setting, as well as the responsiveness of such measures in assessing these practices. 


\section{Acknowledgements}

Acknowledgements: The authors are grateful to all the kindergarten staff who participated in the BRA study. Financial support: This work was supported by the Norwegian Research Council (228452/H10), with supplementary funds from the Throne Holst Nutrition Research Foundation, University of Oslo, Norway. Consent to participate: This study was conducted according to the guidelines laid down in the Declaration of Helsinki, and the Norwegian Center for Research Data approved all procedures involving human subjects. Of 479 kindergartens 73 public and private kindergartens accepted the invitation to participate in the BRA study. Consent for publication: Not applicable. Availability of data and material: Data will be available upon request, provided compliance with the current legislation for application of data access in Norway. Conflict of interest: The authors declare that they have no competing interests. Authorship: A.H.S. conducted statistical analyses and wrote the draft of the manuscript. A.L.K., M.B., N.L. and L.F.A. participated in designing the BRA study. A.H.S., A.L.K., M.B., N.L. and L.F.A. participated in project planning, and A.H.S. and A.L.K. participated in data collection. All authors have critically revised the manuscript and read and approved the final version of the manuscript. Ethics of human subject participation: Not applicable. Trial registration: Trial ID ISRCTN51962956. Retrospectively 21.06.2016.

\section{Supplementary material}

To view supplementary material for this article, please visit https://doi.org/10.1017/\$1368980019003963

\section{References}

1. World Health Organization (2014) Global Status Report on Noncomunicable Diseases 2014: Attaining the Nine Global Noncomunicable Diseases Targets; A Shared Responsibility. Geneva, Switzerland: World Health Organization.

2. Micha R, Khatibzadeh S, Shi P et al. (2015) Global, regional and national consumption of major food groups in 1990 and 2010: a systematic analysis including 266 country-specific nutrition surveys worldwide. $\mathrm{Br}$ Med J 5, e008705. doi: 10. 1136/bmjopen-2015-008705.

3. OECD (2012) Health at a Glance: Europe 2012. Chapter: 2. Determinants of Health. Paris: OECD.

4. Norwegian Directorate of Health (2011) Dietary Advice to Promote Public Health and Reduce Chronic Diseases Methodology and Scientific Knowledge Base National Council for Nutrition (in Norwegian). Report No.: IS-1881.

5. Mikkila V, Rasanen L, Raitakari OT et al. (2005) Consistent dietary patterns identified from childhood to adulthood: the cardiovascular risk in Young Finns Study. Br J Nutr 93 , 923-931.

6. Northstone K \& Emmett PM (2008) Are dietary patterns stable throughout early and mid-childhood? a birth cohort study. $\mathrm{Br}$ J Nutr 100, 1069-1076. doi: 10.1017/S0007114508968264.
7. Bjelland M, Brantsæeter AL, Haugen M et al. (2013) Changes and tracking of fruit, vegetables and sugar-sweetened beverages intake from 18 months to 7 years in the Norwegian mother and child cohort study. BioMed Central Public Health 13, 793. doi: 10.1186/1471-2458-13-793.

8. Totland TH, Gebremariam MK, Lien N et al. (2013) Does tracking of dietary behaviours differ by parental education in children during the transition into adolescence? Public Health Nutr 16, 673-682. doi: 10.1017/S1368980012003060.

9. Cullen KW, Baranowski T, Owens E et al. (2003) Availability, accessibility, and preferences for fruit, 100\% fruit juice, and vegetables influence children's dietary behavior. Health Educ Behav 30, 615-626.

10. Blanchette L \& Brug J (2005) Determinants of fruit and vegetable consumption among 6-12-year-old children and effective interventions to increase consumption. J Human Nutr Diet: Off J Br Diet Assoc 18, 431-443.

11. Brug J, Kremers SP, Lenthe F et al. (2008) Environmental determinants of healthy eating: in need of theory and evidence. Proc Nutr Soc 67, 307-316.

12. Gubbels JS, Kremers SP, Stafleu A et al. (2010) Child-care environment and dietary intake of 2- and 3-year-old children. J Hum Nutr Diet 23, 97-101.

13. Gubbels JS, Gerards SM \& Kremers SP (2015) Use of food practices by childcare staff and the association with dietary intake of children at childcare. Nutrients 7, 2161-2175.

14. Mikkelsen MV, Husby S, Skov LR et al. (2014) A systematic review of types of healthy eating interventions in preschools. Nutr J 13, 56. doi: 10.1186/1475-2891-13-56.

15. Hodder R, Stacey FG, Wyse RJ et al. (2017) Interventions for increasing fruit and vegetable consumption in children aged five years and under. Cochrane Database Syst Rev issue 9, CD008552. doi: 10.1002/14651858.CD008552.pub3.

16. Statistics Norway (2016) Kindergartens, 2016 Final Numbers. https://www.ssb.no/utdanning/statistikker/barnehager (accessed May 2017).

17. Norwegian Directorate of health (2007) Guidelines for Food and Meals in the kindergarten (in Norwegian). helsedirektoratet.no. Report No.: IS-1484.

18. The Norwegian Directorate for Education and Training (2017) Guidelines for the kindergartens Content and Task's (in Norwegian). udir.no/rammeplan.

19. Hoffmann TC, Glasziou PP, Boutron I et al. (2014) Better reporting of interventions: template for intervention description and replication (TIDieR) checklist and guide. $\mathrm{Br} \mathrm{Med} \mathrm{J}$ 348, g1687. doi: https://doi.org/10.1136/bmj.g1687.

20. Himberg-Sundet A, Kristiansen AL, Bjelland M et al. (2018) Is the environment in kindergarten associated with the vegetables served and eaten? The BRA Study. Scand J Public Health 348, g1687. doi: 10.1177/1403494818756702

21. Norwegian Directorate of Health. (2012) Meals, Physical Activity and Environmental Health Care in kindergartens (in Norwegian). helsedirektoratet.no. Report No.: IS-0345.

22. Kristiansen AL, Lande B \& Andersen LF (2009) Småbarnskost 2007 - Dietary Habits Among 2-Year-Old Children in Norway (in Norwegian). Report No.: IS-1731.

23. Baranowski T, Beltran A, Chen T-A et al. (2013) Psychometric assessment of scales for a Model of Goal Directed Vegetable Parenting Practices (MGDVPP). Int J Behav Nutr Phys Act 10, 110. doi: 10.1186/1479-5868-10-110.

24. Haszard JJ, Williams SM, Dawson AM et al. (2013) Factor analysis of the comprehensive feeding practices questionnaire in a large sample of children. Appetite 62, 110-118.

25. Musher-Eizenman D \& Holub S (2007) Comprehensive feeding practices questionnaire: validation of a new measure of parental feeding practices. J Pediatr Psychol 32, 960-972.

26. Zeinstra GG, Koelen MA, Kok FJ et al. (2010) Parental child-feeding strategies in relation to Dutch children's fruit and vegetable intake. Public Health Nutr 13, 787-796. 
27. Vellinga M (2016) Physical and social environmental factors in Norwegian kindergartens and their associations with vegetbale consumption of preschool children - the BRA-study. Master thesis, University of Maastricht.

28. Ward DS, Benjamin SE, Ammerman AS et al. (2008) Nutrition and physical activity in child care: results from an environmental intervention. Am J Prev Med 35, 352-356.

29. Tabachnick BG \& Fidell LS (2018) Using Multivariate Statistics, 7 nd ed. Upper Saddle River: Pearson.

30. Krolner R, Rasmussen M, Brug J et al. (2011) Determinants of fruit and vegetable consumption among children and adolescents: a review of the literature. Part II: qualitative studies. Int J Behav Nutr Phys Act 8, 112. doi: 10.1186/1479-5868-8-112.

31. Norwegian Directorate of Health (2014) Recommendations on Diet, Nutrition and Physical Activity (in Norwegian). helsedirektoratet.no. Report No.: IS-2170.

32. The Norwegian information bureau for fruit and vegetables Totaloversikten 2017 - Aktuell statistikk og innsikt om frukt, bær, grønnsaker og poteter i Norge (In Norwegian) (2017). https://www.frukt.no/globalassets/materiell/totalover sikten/totaloversikten2017-hyperlenker-korr2.pdf (accessed May 2017)

33. Vandeweghe L, Moens E, Braet C et al. (2016) Perceived effective and feasible strategies to promote healthy eating in young children: focus groups with parents, family child care providers and daycare assistants. BioMed Central Public Health 16, 1045. doi: 10.1186/s12889-016-3710-9.

34. Bell AC, Davies L, Finch M et al. (2015) An implementation intervention to encourage healthy eating in centre-based child-care services: impact of the Good for Kids Good for Life programme. Public Health Nutr 18, 1610-1619. doi: $10.1017 /$ s1368980013003364.

35. Kharofa RY, Kalkwarf HJ, Khoury JC et al. (2016) Are mealtime best practice guidelines for child care centers associated with energy, vegetable, and fruit intake? Child Obes (Print) 12, 52-58. 